\title{
Effects of high-flow nasal cannula in patients with mild to moderate hypercapnia: a prospective observational study
}

\author{
Kyung Hun Nam ${ }^{1, *}$, Hyung Koo Kang ${ }^{2}$, Sung-Soon Lee ${ }^{2}$, So-Hee Park², Sung Wook Kang ${ }^{3}$, Jea Jun Hwang ${ }^{3}$, \\ So Young Park ${ }^{4}$, Won Young Kim ${ }^{5}$, Hee Jung Suh ${ }^{6}$, Eun Young Kim ${ }^{6}$, Ga Jin Seo ${ }^{6}$, Younsuck Koh ${ }^{7}$, \\ Sang-Bum Hong ${ }^{7}$, Jin Won Huh ${ }^{7}$, Chae-Man Lim ${ }^{7}$ \\ ${ }^{1}$ Department of Medicine, Ajou University Intermediate Care Hospital, Suwon; ${ }^{2}$ Division of Pulmonary and Critical Care Medicine, Department of Internal \\ Medicine, Inje University Ilsan Paik Hospital, Inje University College of Medicine, Goyang, ${ }^{3}$ Department of Pulmonary and Critical Care Medicine, Kyung \\ Hee University Hospital at Gangdong, Seoul; ${ }^{4}$ Department of Pulmonology, Ewha Womans University Seoul Hospital, Seoul; ${ }^{5}$ Department of Emergency \\ Medicine, Asan Medical Center, University of Ulsan College of Medicine, Seoul; ${ }^{6}$ Intensive Care Nursing Team, Asan Medical Center, Seoul; ${ }^{7}$ Department of \\ Pulmonary and Critical Care Medicine, Asan Medical Center, University of Ulsan College of Medicine, Seoul, Korea
}

Background: Evidence for using high-flow nasal cannula (HFNC) in hypercapnia is still limited. Most of the clinical studies had been conducted retrospectively, and there had been conflicting reports for the effects of HFNC on hypercapnia correction in prospective studies. Therefore, more evidence is needed to understand the effect of the HFNC in hypercapnia. Methods: We conducted a multicenter prospective observational study after applying HFNC to 45 hospitalized subjects who had moderate hypercapnia (arterial partial pressure of carbon dioxide $\left[\mathrm{PaCO}_{2}\right], 43-70 \mathrm{~mm} \mathrm{Hg}$ ) without severe respiratory acidosis $(\mathrm{pH}<7.30)$. The primary outcome was a change in $\mathrm{PaCO}_{2}$ level in the first 24 hours of HFNC use. The secondary outcomes were changes in other parameters of arterial blood gas analysis, changes in respiration rates, and clinical outcomes.

Results: There was a significant decrease in $\mathrm{PaCO}_{2}$ in the first hour of HFNC application (-3.80 $\mathrm{mm} \mathrm{Hg} ; 95 \%$ confidence interval, -6.35 to $-1.24 ; \mathrm{P}<0.001$ ). Reduction of $\mathrm{PaCO}_{2}$ was more prominent in subjects who did not have underlying obstructive lung disease. There was a correction in $\mathrm{pH}$, but no significant changes in respiratory rate, bicarbonate, and arterial partial pressure of oxygen/fraction of inspired oxygen ratio. Mechanical ventilation was not required for $93.3 \%$ (42/45) of our study population.

Conclusions: We suggest that HFNC could be a safe alternative for oxygen delivery in hypercapnia patients who do not need immediate mechanical ventilation. With HFNC oxygenation, correction of hypercapnia could be expected, especially in patients who do not have obstructive lung diseases.

Key Words: carbon dioxide; hypercapnia; mechanical ventilation; nasal cannula

\section{INTRODUCTION}

High-flow nasal cannula (HFNC) is a relatively new device for oxygenation that has become a popular tool in the treatment of hypoxic respiratory failure [1]. Recently, there has been a

\section{Original Article}

Received: December 10, 2020

Revised: April 19, 2021

Accepted: April 19, 2021

\section{Corresponding author}

Chae-Man Lim

Department of Pulmonary and Critical Care Medicine, Asan Medical Center, University of Ulsan College of Medicine, 88 Olympic-ro 43-gil, Songpa-gu, Seoul 05505, Korea Tel: +82-2-3010-4700

Fax: +82-2-2045-4039

E-mail:cmlim@amc.seoul.kr

${ }^{*}$ Current affiliation: Department of Critical Care Medicine, Seongnam Citizens Medical Center, Seongnam, Korea

Copyright (ㄷ 2021 The Korean Society of Critical Care Medicine

This is an Open Access article distributed under the terms of Creative Attributions Non-Commercial License (https:// creativecommons.org/li-censes/by-nc/4.0/) which permits unrestricted noncommercial use, distribution, and reproduction in any medium, provided the original work is properly cited. 
growing interest in its use in hypercapnia. Physiological studies have shown that HFNC reduces rebreathing of carbon dioxide in the upper and lower anatomical dead space $[2,3]$. HFNC users generate less carbon dioxide by reduced work of breathing [4]. Some studies have also suggested that HFNC may even improve alveolar ventilation [5]. However, the effectiveness of HFNC in hypercapnic respiratory failure has not been fully demonstrated as relevant studies have been mostly retrospective with some contradictory results [6-8].

To clearly understand the effects of HFNC in hypercapnic respiratory failure, we conducted a prospective observational study with frequent arterial blood gas analysis (ABGA) in the first 24 hours after starting HFNC. For safety reasons, we recruited patients with mild to moderate hypercapnia without severe acidosis. The aim of this study was to examine the competence of HFNC in hypercapnia correction and to investigate the clinical use of HFNC in patients with hypercapnia.

\section{MATERIALS AND METHODS}

A multicenter prospective observational study was conducted in four tertiary care hospitals in South Korea from November 2017 to October 2018. Inclusion criteria for the subjects were patients with mild to moderate hypercapnia ( $43 \leq$ arterial partial pressure of carbon dioxide $\left[\mathrm{PaCO}_{2}\right] \leq 70 \mathrm{~mm} \mathrm{Hg}$ ) in ABGA. Recruitment was conducted from the emergency room, general ward, and intensive care unit. Exclusion criteria were: under 18 years of age; respiratory rate more than 35 breaths per minute; severe acidosis ( $\mathrm{pH}<7.30)$; using accessory muscle of respiration; any other signs of progressive respiratory failure requiring imminent intubation and mechanical ventilation; unstable hemodynamics; post-cardiopulmonary resuscitation status or on extracorporeal membrane oxygenation; consciousness disorder that would require intubation (e.g., not responsive, agitated, uncooperative, high risk for aspiration); facial surgery, trauma or deformity and airway obstruction that precluded application of nasal cannula; and those receiving end-of-life care.

HFNC was initiated with a pulse oximeter oxygen saturation target of $92 \%$. The initial flow was set at $35 \mathrm{~L} / \mathrm{min}$ and adjusted to suit the best comfort of the subject. ABGA was checked at 1 , 3,6 , and 24 hours after starting HFNC. When the 24-hour data collecting period ended, the attending physician decided on the continuation and duration of the HFNC. Medications such as bronchodilators and antibiotics were administered to treat the underlying medical condition and precipitating factors.

\section{KEY MESSAGES}

- When high-flow nasal cannula was applied in moderate hypercapnia patients without severe respiratory acidosis, reduction of carbon dioxide and correction of $\mathrm{pH}$ was seen.

- Progression to mechanical ventilation was comparable to previous studies.

- We suggest that high-flow nasal cannula could be a safe alternative for oxygen delivery in hypercapnia patients who do not need immediate mechanical ventilation.

HFNC was discontinued if the subject met any of the following criteria: symptoms and signs of worsening respiratory distress, such as retractions or sweating; increased respiratory rate to more than 35 breaths per minute; elevation of $\mathrm{PaCO}_{2}$ greater than $10 \mathrm{~mm} \mathrm{Hg}$ from the previous ABGA results; $\mathrm{pH}$ less than 7.2 in any of the ABGA results; $\mathrm{pH}$ decrease more than 0.2 from previous ABGA results; or deteriorating mental status.

\section{Study Outcomes}

The primary outcome was change in ABGA parameters during the first 24 hours of HFNC application. We also analyzed change in $\mathrm{PaCO}_{2}$ based on underlying lung conditions. We hypothesized that the reduction in $\mathrm{PaCO}_{2}$ would be greater in patients with an obstructive pulmonary pathology. The secondary outcome was the clinical course of the subjects during hospitalization, which included discontinuation of HFNC according to the criteria, progression to invasive or noninvasive mechanical ventilation, and death.

\section{Statistical Analysis}

One-way repeated measure analysis of variance with a post hoc test by Bonferroni correction was used to evaluate the changes in ABGA parameters. Descriptive statistics were used for the clinical courses of subjects. The level of significance was set at 0.05. IBM SPSS ver. 25 (IBM Corp., Armonk, NY, USA) was used for all analyses.

\section{Ethics Statement}

The Institutional Review Boards of each participating hospital approved the study and written informed consent was obtained from all study participants prior to initial observation. This study is registered in the Korean Clinical Research Information Service (CRIS, https://cris.nih.go.kr; registration No. KCT0003448). 


\section{RESULTS}

\section{Study Population}

A total of 51 subjects were recruited for the study. Six subjects dropped out of the study due to discomfort associated with HFNC (Figure 1). The general characteristics of the 45 study subjects are reported (Table 1). The most common acute lung condition was pneumonia followed by pulmonary edema and chronic obstructive pulmonary disease (COPD) exacerbation. In total, $87 \%$ (39/45) of the patients were receiving conventional oxygen therapy at the time of enrolment. For the initial HFNC settings, the median fraction of inspired oxygen $\left(\mathrm{FiO}_{2}\right)$ provided was $32 \%$ with a median flow of $35 \mathrm{~L} / \mathrm{min}$.

\section{Primary Outcome}

Changes in ABGA parameters are illustrated (Figure 2). There were significant $\mathrm{pH}$ and $\mathrm{PaCO}_{2}$ changes after HFNC application (Table 2). For $\mathrm{PaCO}_{2}$, a significant decrease was observed between the baseline and 1-hour measurement $(-3.80 \mathrm{~mm}$ Hg; 95\% confidence interval $[\mathrm{CI}],-6.35$ to $-1.24 ; \mathrm{P}<0.001$ ). Among other checkpoints, there were no significant differences. Similarly, for $\mathrm{pH}$, a significant increase was observed between the baseline and 1-hour measurement $(0.030$; 95\% CI, 0.050-0.010; $\mathrm{p}<0.001)$. In other parameters such as arterial bicarbonate concentration $\left(\mathrm{HCO}_{3}\right)$ and arterial partial pres-

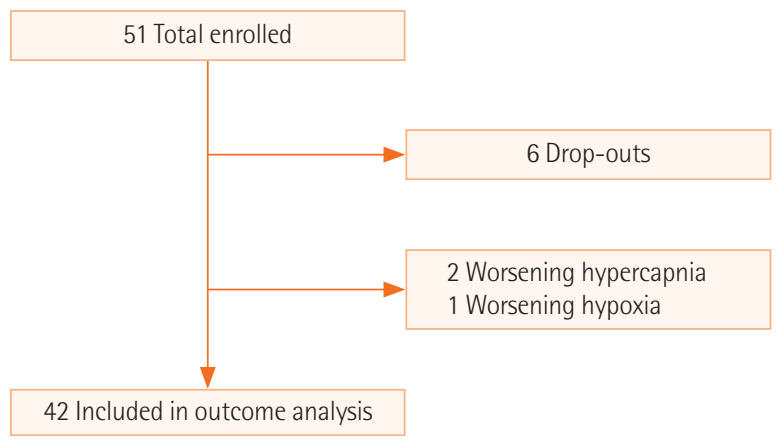

Figure 1. Flow of study participants. sure of oxygen/fraction of inspired oxygen ratio, no significant differences were observed between checkpoints.

$\mathrm{PaCO}_{2}$ changes in the obstructive and non-obstructive groups We analyzed changes in $\mathrm{PaCO}_{2}$ after grouping the subjects based on underlying lung diseases. The "obstructive group" included subjects who had previously been diagnosed with obstructive lung disease: COPD, chronic bronchitis, emphysema, bronchiectasis and asthma. The "non-obstructive group" included subjects who had no documented obstructive lung disease. There were 18 subjects in the obstructive group and 24 in the non-obstructive group. Between the two groups, there was no statistical difference in age, sex, BMI, baseline ABGA

Table 1. General characteristics of enrolled subjects

\begin{tabular}{lc}
\hline Characteristics & Total $(n=45)$ \\
\hline Demographics & $70(62-81)$ \\
Age $(\mathrm{yr})$ & $27(60.0)$ \\
Male sex & $21.3(18.0-25.2)$ \\
BMI (kg/m²) & \\
Acute lung condition & $23(48.9)$ \\
Pneumonia & $15(33.3)$ \\
Pulmonary edema & $12(26.7)$ \\
COPD exacerbation & $6(13.3)$ \\
Atelectasis & $3(6.7)$ \\
Asthma exacerbation & \\
Baseline conventional $\mathrm{O}_{2}$ & $32(71.1)$ \\
Nasal prong & $7(15.6)$ \\
Face mask & \\
Initial HFNC setting & $32(25-37)$ \\
FiO 2 (\%) & $35(30-37.5)$ \\
Flow (L/min) &
\end{tabular}

Values are presented as median (interquartile range) or number (\%). BMI: body mass index; COPD: chronic obstructive pulmonary disease; HFNC: high-flow nasal cannula oxygen therapy; $\mathrm{FiO}_{2}$ : fraction of inspired oxygen.

Table 2. Changes in parameters of arterial blood gas analysis after high-flow nasal cannula application

\begin{tabular}{lcccccc}
\hline Variable & Baseline & $1 \mathrm{hr}$ & $3 \mathrm{hr}$ & $6 \mathrm{hr}$ & $24 \mathrm{hr}$ & $\mathrm{P}$-value \\
\hline $\mathrm{pH}$ & $7.402 \pm 0.05$ & $7.431 \pm 0.06$ & $7.436 \pm 0.05$ & $7.435 \pm 0.05$ & $7.444 \pm 0.05$ & $<0.001$ \\
$\mathrm{PaCO}_{2}(\mathrm{~mm} \mathrm{Hg})$ & $52.8 \pm 6.8$ & $49.0 \pm 9.0$ & $47.6 \pm 7.0$ & $46.9 \pm 7.0$ & $45.9 \pm 8.3$ & $<0.001$ \\
$\mathrm{P} / \mathrm{F}$ ratio & $99 \pm 93$ & $294 \pm 134$ & $288 \pm 108$ & $296 \pm 105$ & $283 \pm 96$ & 0.826 \\
$\mathrm{HCO}_{3}(\mathrm{mEq} / \mathrm{L})$ & $31.8 \pm 5.3$ & $32.2 \pm 5.0$ & $32.0 \pm 4.4$ & $31.6 \pm 4.5$ & $31.4 \pm 4.5$ & 0.518 \\
\hline
\end{tabular}

Values are presented as mean \pm standard deviation.

hr: hours after high-flow nasal cannula application; $\mathrm{PaCO}_{2}$ : arterial partial pressure of carbon dioxide; $\mathrm{P} / \mathrm{F}$ ratio: arterial partial pressure of oxygen/fraction of inspired oxygen $\left(\mathrm{PaO}_{2} / \mathrm{FiO}_{2}\right)$ ratio; $\mathrm{HCO}_{3}$ : arterial bicarbonate concentration. 

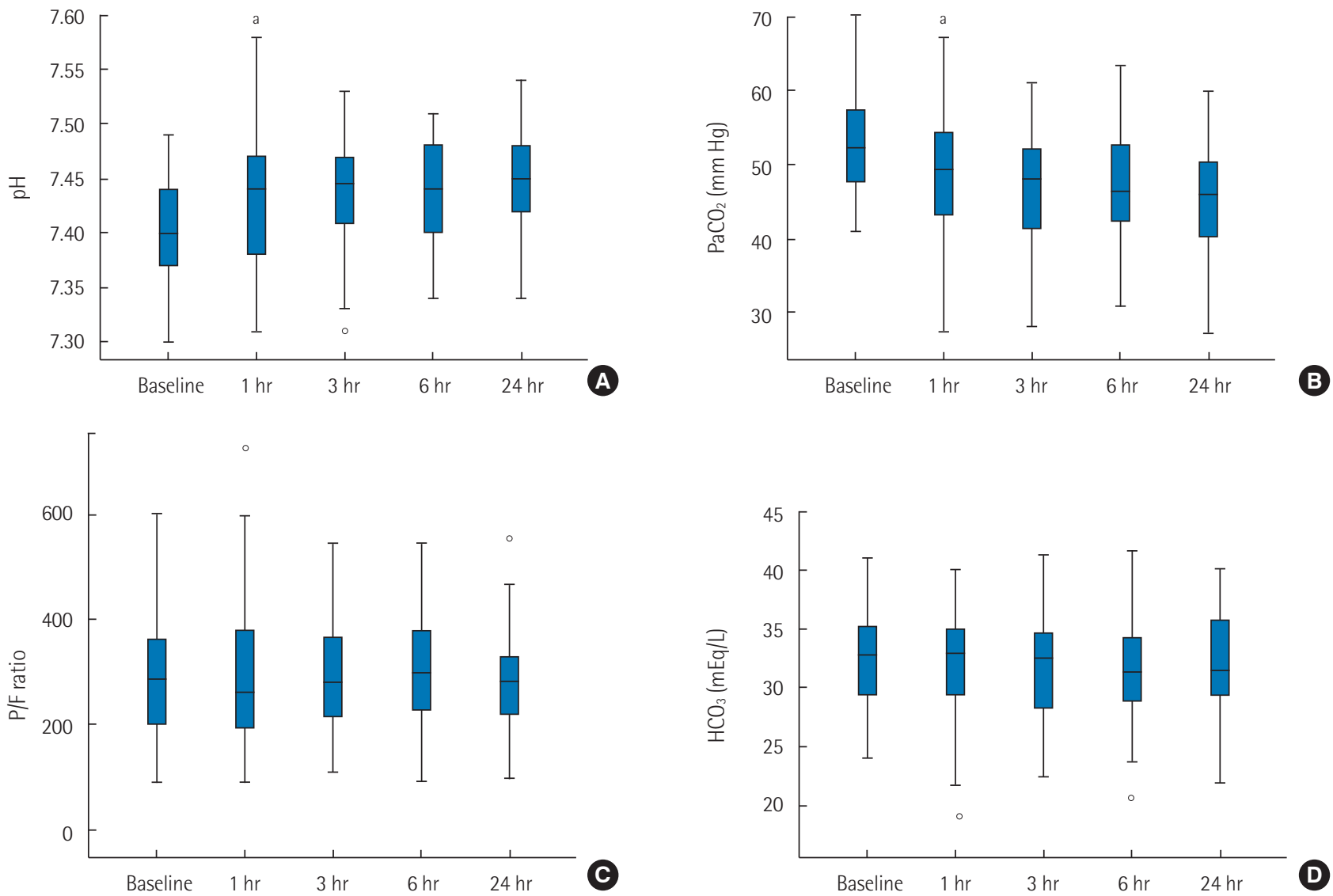

Figure 2. Change in arterial blood gas analysis parameters at baseline, 1, 3, 6, and 24 hours after applying high-flow nasal cannula. (A) pH. (B) Arterial partial pressure of carbon dioxide $\left(\mathrm{PaCO}_{2}\right)$. (C) Arterial partial pressure of oxygen/fraction of inspired oxygen $\left(\mathrm{PaO}_{2} / \mathrm{FiO} \mathrm{O}_{2}\right)$ ratio $(\mathrm{P} / \mathrm{F}$

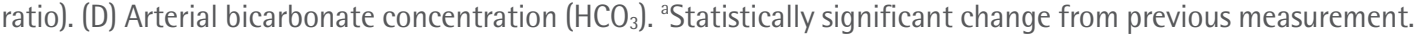
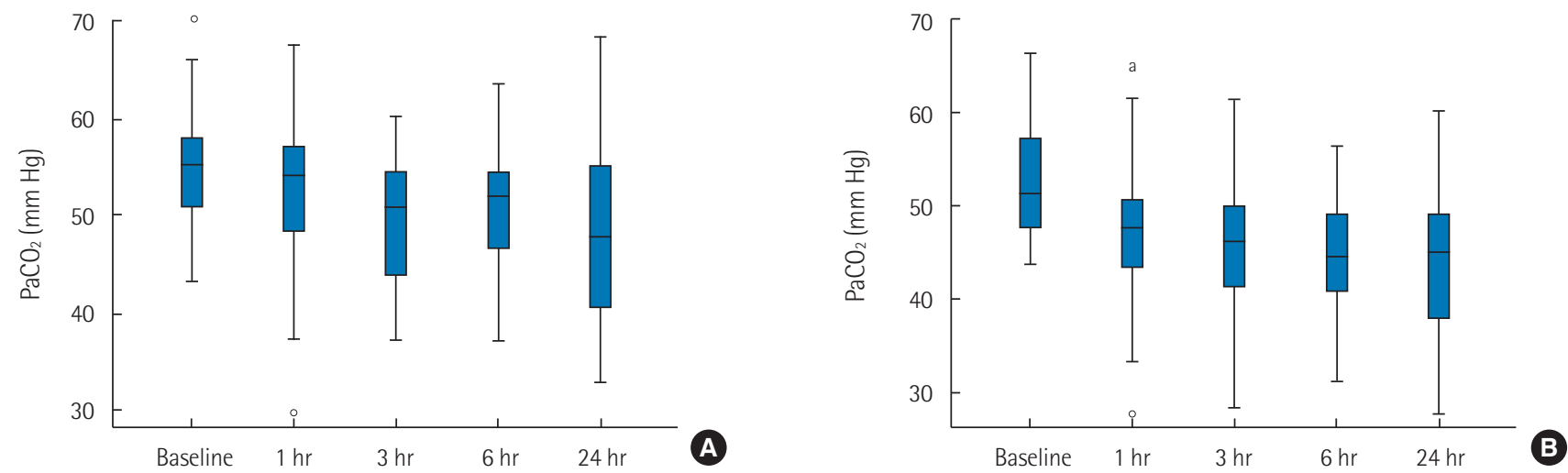

Figure 3. Change in arterial partial pressure of carbon dioxide $\left(\mathrm{PaCO}_{2}\right)$ at baseline, $1,3,6$, and 24 hours after applying high-flow nasal can-

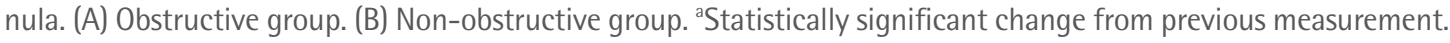

results, and the initial HFNC setting.

$\mathrm{PaCO}_{2}$ changes in separate groups are illustrated (Figure 3). In the obstructive group, mean $\mathrm{PaCO}_{2}$ decreased from 54.2 to 51.8, 49.7, 49.6, and $48.3 \mathrm{~mm} \mathrm{Hg}$. These changes were not statistically significant $(\mathrm{P}=0.075)$. However, a significant decrease of $\mathrm{PaCO}_{2}$ was also found in the non-obstructive group. As mean
$\mathrm{PaCO}_{2}$ decreased from 51.7 to $46.9,46.0,44.8$, and $44.2 \mathrm{~mm} \mathrm{Hg}$, there was a significant decrease between baseline and 1-hour measurement (-4.83 mm Hg; 95\% CI, -8.4 to -1.3 ; $\mathrm{P}<0.001$ ).

\section{Secondary Outcome}

Among the 45 study subjects, three subjects (6.7\%) met the 
criteria for HFNC discontinuation. Two patients had an increase in $\mathrm{PaCO}_{2}$ of more than $10 \mathrm{~mm} \mathrm{Hg}$, and one patient showed symptoms and signs of worsening respiratory distress. Noninvasive ventilation was applied to the two patients with worsening hypercapnia. Invasive mechanical ventilation was applied to the patient with worsening respiratory distress. For the remainder of the 42 subjects, HFNC was continued for an average of 47 hours (median, 33 hours; interquartile range, 24-70 hours). No deaths were observed among the study population.

\section{DISCUSSION}

In this prospective observational study, we report our findings on changes in ABGA parameters after applying HFNC to patients with mild to moderate hypercapnia. A significant decrease in $\mathrm{PaCO}_{2}$ and $\mathrm{pH}$ correction were observed in the first hour of HFNC application. The effect of $\mathrm{PaCO}_{2}$ reduction was more prominent in patients who did not have underlying obstructive lung disease. In terms of clinical outcomes of the 45 study subjects, two subjects required noninvasive mechanical ventilation for worsening hypercapnia, and one subject required invasive mechanical ventilation after intubation for worsening respiratory distress. There were no deaths or serious adverse outcomes in the study population.

With its unique physiological benefits, HFNC has become a popular device for oxygen delivery. HFNC provides a constant $\mathrm{FiO}_{2}$, improves mucociliary clearance, reduces the effort required to breathe, and decreases anatomical dead space [1]. With acute hypoxic respiratory failure, multiple prospective randomized trials have shown the clinical advantages of HFNC over conventional oxygen delivery systems $[9,10]$. Therefore, HFNC is widely being used in various conditions with hypoxia.

However, the effects of HFNC on hypercapnic respiratory failure remain unclear; therefore, more evidence is needed to support its use in patients with hypercapnia. Although most clinical studies have reported a reduction in $\mathrm{PaCO}_{2}$ after applying HFN, there have been some studies with conflicting results. In a study by Sztrymf et al. [8], involving intensive care unit patients with acute respiratory failure, a significant increase in $\mathrm{PaCO}_{2}$ was observed. In a study by Nilius et al. [11], the use of HFNC resulted in different individual responses in respiratory rates and $\mathrm{PaCO}_{2}$ levels.

Because hypercapnia has complex pathophysiological mechanisms and multiple etiologies, there is wide heterogeneity in patients [12]. This could explain the mixed results in clinical studies and becomes a challenge to establishing clear indica- tions for the use of HFNC in hypercapnic respiratory failure. However, even with various causes, there are commonalities in these patients. Whatever the diagnosis, mechanical ventilation (invasive and noninvasive) is a standard treatment in severe cases of hypercapnia [13]. Therefore, the potential $\mathrm{CO}_{2}$ removal capacity and physiologic benefits make HFNC an attractive alternative to conventional oxygen therapy in patients with hypercapnia.

With our study, an overall decrease in $\mathrm{PaCO}_{2}$ with a correction of $\mathrm{pH}$ was observed after applying HFNC in patients with mild to moderate hypercapnia. Additionally, $93 \%$ of the study population was successfully treated without progressing to mechanical ventilation. In other studies investigating clinical implications of HFNC on hypercapnic respiratory failure, in tubation rate ranged from $0 \%$ to $25 \%[14,15]$. A recent metaanalysis suggested that HFNC was not inferior to noninvasive ventilation with respect to intubation rate and mortality [16]. Considering all current evidence, HFNC may be a feasible alternative option for oxygen supplementation in patients with mild to moderate hypercapnia.

However, our study found a different response to HFNC depending on underlying lung disease. We analyzed changes in $\mathrm{PaCO}_{2}$ after grouping the patients according to the presence or absence of an obstructive lung pathology. Contrary to our anticipation, the effects of HFNC were more pronounced in patients who did not have underlying obstructive lung disease. This finding suggests that the decrease in $\mathrm{PaCO}_{2}$ during HFNC was possibly related to the decreased effort required to breathe rather than reduction in dead space. Further studies are needed to better understand the effects of HFNC on hypercapnia based on underlying lung pathology.

We recognize the limitations of this study. We acknowledge that the findings in this study cannot be fully accepted without a control group comparison. Also, because of the nature of this study design, selection bias is possible. Last, the small number of subjects also limits the ability to generalize the study's findings.

In conclusion, we prospectively investigated changes in ABGA parameters and clinical implications of HFNC in patients with mild to moderate hypercapnia. After applying HF$\mathrm{NC}$, an overall decrease in $\mathrm{PaCO}_{2}$ with $\mathrm{pH}$ correction was seen. Most of our subjects were treated successfully without progressing to mechanical ventilation. Therefore, we suggest that HFNC could be a feasible alternative option for oxygen delivery in patients with mild to moderate hypercapnia. However, further controlled studies with different etiologies of hypercapnia are needed to establish the clear role of HFNC in pa- 
tients with hypercapnic respiratory failure.

\section{CONFLICT OF INTEREST}

No potential conflict of interest relevant to this article was reported.

\section{ACKNOWLEDGMENTS}

Funding was provided by the Korea Health Industry Development Institute (https://www.khidi.or.kr; grant No. HI17C0263). High-flow nasal cannula device was sponsored by MEK-ICS, South Korea (http://mek-ics.com). Neither had a role in the study.

\section{ORCID}

$\begin{array}{ll}\text { Kyung Hun Nam } & \text { https://orcid.org/0000-0002-8991-134X } \\ \text { Hyung Koo Kang } & \text { https://orcid.org/0000-0001-9671-0944 } \\ \text { Sung-Soon Lee } & \text { https://orcid.org/0000-0001-6422-2313 } \\ \text { So-Hee Park } & \text { https://orcid.org/0000-0002-3320-9949 } \\ \text { Sung Wook Kang } & \text { https://orcid.org/0000-0002-3062-2527 } \\ \text { Jea Jun Hwang } & \text { https://orcid.org/0000-0003-1832-1024 } \\ \text { So Young Park } & \text { https://orcid.org/0000-0003-2718-0518 } \\ \text { Won Young Kim } & \text { https://orcid.org/0000-0002-6904-5966 } \\ \text { Hee Jung Suh } & \text { https://orcid.org/0000-0001-5931-9030 } \\ \text { Eun Young Kim } & \text { https://orcid.org/0000-0002-7984-0517 } \\ \text { Ga Jin Seo } & \text { https://orcid.org/0000-0002-4255-1869 } \\ \text { Younsuck Koh } & \text { https://orcid.org/0000-0001-5066-2027 } \\ \text { Sang-Bum Hong } & \text { https://orcid.org/0000-0003-2737-7695 } \\ \text { Jin Won Huh } & \text { https://orcid.org/0000-0002-3449-0461 } \\ \text { Chae-Man Lim } & \text { https://orcid.org/0000-0001-5400-6588 }\end{array}$

\section{AUTHOR CONTRIBUTIONS}

Conceptualization: KHN, WYK, CML. Data curation: KHN, HJS, EYK, GJS. Formal analysis: KHN. Funding acquisition: CML. Methodology: all authors. Project administration: CML, KHN. Investigation: all authors. Visualization: KHN. Writingoriginal draft: KHN. Writing-review \& editing: CML.

\section{REFERENCES}

1. Drake MG. High-flow nasal cannula oxygen in adults: an evidence-based assessment. Ann Am Thorac Soc 2018;15:14555.

2. Möller W, Celik G, Feng S, Bartenstein P, Meyer G, Oliver E, et al. Nasal high flow clears anatomical dead space in upper airway models. J Appl Physiol (1985) 2015;118:1525-32.

3. Bräunlich J, Goldner F, Wirtz H. Nasal highflow eliminates CO2 from lower airways. Respir Physiol Neurobiol 2017;242: 86-8.

4. Biselli PJ, Kirkness JP, Grote L, Fricke K, Schwartz AR, Smith P, et al. Nasal high-flow therapy reduces work of breathing compared with oxygen during sleep in COPD and smoking controls: a prospective observational study. J Appl Physiol (1985) 2017;122:82-8.

5. Patel A, Nouraei SA. Transnasal humidified rapid-insufflation ventilatory exchange (THRIVE): a physiological method of increasing apnoea time in patients with difficult airways. Anaesthesia 2015;70:323-9.

6. Jeong JH, Kim DH, Kim SC, Kang C, Lee SH, Kang TS, et al. Changes in arterial blood gases after use of high-flow nasal cannula therapy in the ED. Am J Emerg Med 2015;33:1344-9.

7. Kim ES, Lee H, Kim SJ, Park J, Lee YJ, Park JS, et al. Effectiveness of high-flow nasal cannula oxygen therapy for acute respiratory failure with hypercapnia. J Thorac Dis 2018;10:882-8.

8. Sztrymf B, Messika J, Mayot T, Lenglet H, Dreyfuss D, Ricard JD. Impact of high-flow nasal cannula oxygen therapy on intensive care unit patients with acute respiratory failure: a prospective observational study. J Crit Care 2012;27:324.e9-13.

9. Frat JP, Thille AW, Mercat A, Girault C, Ragot S, Perbet S, et al. High-flow oxygen through nasal cannula in acute hypoxemic respiratory failure. N Engl J Med 2015;372:2185-96.

10. Rochwerg B, Granton D, Wang DX, Helviz Y, Einav S, Frat JP, et al. High flow nasal cannula compared with conventional oxygen therapy for acute hypoxemic respiratory failure: a systematic review and meta-analysis. Intensive Care Med 2019; 45:563-72.

11. Nilius G, Franke KJ, Domanski U, Rühle KH, Kirkness JP, Schneider $\mathrm{H}$. Effects of nasal insufflation on arterial gas exchange and breathing pattern in patients with chronic obstructive pulmonary disease and hypercapnic respiratory failure. Adv Exp Med Biol 2013;755:27-34.

12. Roussos C, Koutsoukou A. Respiratory failure. Eur Respir J Suppl 2003;47:3s-14s.

13. Davidson AC, Banham S, Elliott M, Kennedy D, Gelder C, Glossop A, et al. BTS/ICS guideline for the ventilatory management of acute hypercapnic respiratory failure in adults. Thorax 2016;71 Suppl 2:iil-35.

14. Papachatzakis Y, Nikolaidis PT, Kontogiannis S, Trakada G. High-flow oxygen through nasal cannula vs. non-invasive ventilation in hypercapnic respiratory failure: a randomized clinical trial. Int J Environ Res Public Health 2020;17:5994. 
15. Lee MK, Choi J, Park B, Kim B, Lee SJ, Kim SH, et al. High flow nasal cannulae oxygen therapy in acute-moderate hypercapnic respiratory failure. Clin Respir J 2018;12:2046-56.
16. Huang Y, Lei W, Zhang W, Huang JA. High-flow nasal cannula in hypercapnic respiratory failure: a systematic review and meta-analysis. Can Respir J 2020;2020:7406457. 